\title{
Aspectos morfológicos da utilização intraperitoneal de prótese de dupla face na inguinoplastia em cães
}

\section{Morphological features of utilization intraperitoneal double-sided prostheses in inguinoplasty in dogs}

luiz Carlos de Andrade, TCBC-MG ${ }^{1}$; Reginaldo Ceneviva, ECBC-SP2; Joaquim Coutinho-Netto3; Orlando de Castro e Silva Júnior, TCBC-SP4; José Sebastião dos Santos, TCBC-SP5; Daniel HiRoChi Sukeda ${ }^{6}$

\section{RE S U M O}

\begin{abstract}
Objetivo: Avaliar os aspectos morfológicos do comportamento de prótese de dupla face aplicada em inguinoplastia laparotômica em cães, com fixação intraperitoneal com a face de látex voltada às vísceras. Métodos: Vinte cães distribuídos em dois grupos $(n=10)$ foram submetidos à laparotomia infraumbilical com fixação da prótese de dupla face em uma região inguinal e de uma prótese controle de polipropileno contralateral. Foram pesquisados no $14^{\circ}$ e $28^{\circ}$ dia de pós-operatório achados macroscópicos referentes à obstrução e fístula intestinais, encistamento, incorporação e aderências. A análise microscópica envolveu o processo inflamatório e reparador. Resultados: Não ocorreram processos infecciosos, obstrução ou fístula intestinal. As próteses apresentaram boa acomodação e incorporação. As aderências ocorreram em maior prevalência e intensidade com a prótese de polipropileno $(p<0,05)$. As aderências com a borda da prótese de dupla face ocorreram em $65 \%$ na média dos grupos, sendo que, destas, 35\% em média a aderência se fazia com o disco de polipropileno na face parietal. A análise dos achados microscópicos não mostrou diferença estatística entre as próteses $(p>0,05)$. Conclusão: A prótese de dupla face na sua face parietal soma as vantagens do potencial de incorporação aos tecidos observados com o polipropileno às de biocompatibilidade do látex na sua face visceral. A pequena distância entre o disco de polipropileno e a borda da prótese de dupla face $(2 \mathrm{~cm})$ aliada à sua fixação com apenas cinco grampos é insuficiente para evitar que o epíploon migre em direção ao processo inflamatório desencadeado pelo polipropileno na face parietal.
\end{abstract}

Descritores: Hérnia. Cavidade peritoneal. Prótese. Polipropilenos. Látex. Cães.

\section{INTRODUÇÃO}

A hérnia inguinal tem prevalência alta e, em princípio, requer tratamento cirúrgico ${ }^{1}$.

No Brasil, segundo o Sistema Único de Saúde (SUS), de 1993 a 1996 foram realizadas mais de 500 mil correções cirúrgicas de hérnias inguinais primárias. Estes procedimentos ocuparam o $2^{\circ}$ lugar $(5,3 \%)$ entre todos os realizados no período, consumindo dos cofres públicos mais de 100 milhões de reais. A despeito das diversas técnicas empregadas, a taxa média de recidiva é elevada, em torno de $10 \%$, podendo chegar a índices alarmantes como $30 \%$.

Edoardo Bassini (1884) revolucionou o tratamento da hérnia inguinal ao descrever a operação que é considerada a base da herniorrafia moderna ${ }^{3}$.

Em 1950, no Canadá, Shouldice desenvolveu técnica que reforça a parede posterior do canal inguinal com superposição dos folhetos da fáscia transversal com taxas de recidiva inferiores a $1 \%{ }^{4}$.
Apesar dos bons resultados relatados por Shouldice, e contrariando opositores ao uso de prótese $\mathrm{e}^{5}$, as alarmantes taxas de recorrência levaram autores a buscarem novas técnicas empregando próteses no tratamento dos defeitos herniários.

Com base nos trabalhos pioneiros de Usher $(1959)^{6}$ nos EUA, de Falci (1969)7 no Brasil e de Stoppa $(1972)^{8}$ na Europa, surge uma nova era do emprego de próteses que ganhou maior popularidade após as publicações de Lichteinstein $(1976)^{9}$ sobre uma nova modalidade de hernioplastia baseada no conceito de reforço com prótese, sem tensão, da parede posterior do canal inguinal ${ }^{9}$.

Em 1990, Fitzgibbons, Salermo e Filipi ${ }^{10}$ desenvolveram um projeto de pesquisa em porcos com hérnia inguinal indireta congênita, com o objetivo de avaliar os resultados do tratamento das hérnias inguinais com tela de polipropileno (PPL) intraperitoneal. Os resultados dessa técnica foram considerados bons e os autores a denominaram de Intraperitoneal On Lay Mesh (IPOM) e sugeriram conti-

Trabalho realizado no Laboratório de Técnica Cirúrgica e Cirurgia Experimental do Departamento de Anatomia e Cirurgia da Faculdade de Medicina de Ribeirão Preto FMRP-USP, Ribeirão Preto, SP, Brasil.

1. Professor Titular do Departamento de Clínica Cirúrgica da FCM-UNIFENAS-MG-BR. 2. Professor Titular do Departamento de Cirurgia e Anatomia da FMRP-USP- SP-BR. 3. Professor Titular do Departamento de Bioquímica e Imunologia da FMRP-USP-SP-BR. 4. Professor Titular do Departamento de Cirurgia e Anatomia da FMRP-USP-SP-BR. 5. Professor Associado do Departamento de Cirurgia e Anatomia da FMRP-USP-SPBR. 6. Acadêmico do $6^{\circ}$ ano de Medicina da FCM-UNIFENAS-MG-BR. 
nuar os estudos em humanos. Houve grande entusiasmo inicial pela facilidade técnica, mas logo foram identificadas desvantagens relacionadas ao potencial do PPL em desenvolver aderências, obstrução e fístulas intestinais.

Mais tarde Fitzgibbons passou a utilizar o politetrafluroetileno (PTFE) ao invés do PPL e apresentou uma série de 73 casos com seguimento de 14 meses sem recorrência ${ }^{11}$.

Em 1995 foi desenvolvida e descrita por Mrué ${ }^{12}$ a biomembrana de látex (BML) a partir do látex extraído da árvore Hevea brasiliensis (seringueira). Demonstrou nesta ocasião que a nova prótese no esôfago de cães induziu angiogênese e formação de mucosa e fibras musculares. Mrué (2000) demonstrou em peritoniostomia em cães que a BML, além de angiogênese, induzia a formação de matriz provisional e adesão celular ${ }^{13}$. Sousa (2005) demonstrou que a BML não se adere a tecidos circunjacentes ${ }^{14}$.

Com base nos conhecimentos existentes sobre o potencial de incorporação do PPL pelos tecidos, aliado à biocompatibilidade da BML e à facilidade do tratamento das hérnias inguinocrurais pela técnica IPOM, propôs-se estudar experimentalmente o comportamento de uma prótese de dupla face (BML/PPL) implantada na região inguinal intraperitoneal em cães.

\section{MÉTODOS}

Este trabalho seguiu as normas regulamentadoras da legislação brasileira para o uso de animais de laboratório em experimentação (Lei 6.638), normativas do COBEA (Res. 196/96) e foi aprovada pela Comissão de Ética em Experimentação Animal (CETEA) da Faculdade de Medicina de Ribeirão Preto (FMRP-USP) em 26 de março de 2007, conforme protocolo número 017/2007. O experimento foi realizado no Laboratório de Técnica Cirúrgica e Cirurgia Experimental do Departamento de Anatomia e Cirurgia da FMRP-USP.

Foram utilizados 20 cães mestiços (Canis familiaris), adultos, fêmeas, com peso variando entre $10 \mathrm{e}$ $16 \mathrm{~kg}$, sem hérnia inguinal, fornecidos pelo Biotério Geral do Campus de Ribeirão Preto da USP.
Os animais selecionados foram aleatoriamente distribuídos em dois grupos contendo 10 cães cada, denominados $A$ e $B$ e cada animal foi seu próprio controle.

Cada animal recebeu na região inguinal uma prótese de DF (teste) e na região contralateral uma prótese de PPL (controle).

A definição dos grupos relacionou-se ao tempo de observação pós-operatório. Os animais do grupo A foram submetidos à eutanásia no $14^{\circ}$ dia de pós-operatório e os dos grupos B no $28^{\circ}$ dia.

\section{Prótese}

Em um trabalho conjunto entre o Departamento de Cirurgia e Anatomia e o de Bioquímica e Imunologia da FMRP-USP desenvolveu-se uma prótese de DF para inguinoplastia em cães a ser fixada com a face de látex voltada para as vísceras (Tabela 1).

A partir do látex natural preparou-se um composto por meio da adição de substâncias químicas, visando conferir ao produto final (prótese) características como resistência, suavidade, impermeabilidade e hipoalergenicidade, para que assuma o papel de "manchão" na região inguinocrural.

\section{Procedimento cirúrgico}

Encerrado o período de quarentena no biotério geral, os cães em grupos de dois, aleatoriamente sorteados, foram encaminhados ao Laboratório de Cirurgia Experimental da FMRP-USP. A alimentação foi de água e ração ad libitum até 12 horas antes da operação.

Os animais foram pesados e anestesiados inicialmente com cetamina e xilasina no músculo quadríceps femoral seguido de imobilização em decúbito dorsal em goteira de Claude Bernard. Acessada a veia cefálica, administrou-se thionembutal sódico, como manutenção anestésica, e solução hidroeletrolítica e calórica. Na sequência, o animal foi submetido à intubação orotraqueal com cânula portex 7,5mm e mantido em ventilação mecânica com oxigênio a $100 \%$ à pressão de $2,5 \mathrm{mmHg}$. Concomitantemente ao pré-anestésico foram administradas penicilina benzatina 1200000 UI e penicilina procaína 400000 UI no músculo contralateral.

Tabela 1 - Propriedades morfológicas macroscópicas das próteses.

\begin{tabular}{lll}
\hline Prótese & Dupla face (teste) & Polipropileno (controle) \\
\hline Formato & Circular & Circular \\
Diâmetro & $\mathrm{BML}-5 \mathrm{~cm}$ & $5 \mathrm{~cm}$ \\
& $\mathrm{PPL}-3 \mathrm{~cm}$ & \\
Face & Parietal: BML+PPL & $\mathrm{PPL}$ \\
& Visceral: látex & $\mathrm{PPL}$ \\
Espessura da borda & Grupo A: $1 \mathrm{~mm}$ & $0,5 \mathrm{~mm}$ \\
& Grupo B: $1 \mathrm{~mm}$ & \\
Cor & Amarela & Branca \\
Elasticidade & Pequena & Inelástica \\
Porosidade & Impermeável na face visceral & Poros de $0,5 \mathrm{~mm}$ \\
\hline
\end{tabular}


Realizou-se antissepsia com álcool iodado a $2 \%$, e fez-se a colocação de campo cirúrgico e, ao atingir o plano anestésico, foi feita uma incisão mediana infraumbilical de 8 a $10 \mathrm{~cm}$ com abertura da parede por planos. As próteses foram fixadas com cinco grampos de titânio de 5,3X3,7 mm aplicados com grampeador endoscópico.

Os procedimentos referentes à acomodação, dieta e anestesia dos cães foram iguais aos da primeira operação.

Após a avaliação das regiões inguinais, a área que englobava a prótese foi removida mediante excisão em bloco, juntamente com as vísceras e omento a ela aderidos.

Após o fechamento da cavidade abdominal, o animal foi submetido à eutanásia com thionembutal sódico.

As peças foram esticadas e fixadas em tabletes de isopor com alfinetes de diferentes cores para cada região e imersas em posição inversa em solução de formol tamponado a 10\%, onde ficaram em estágio de fixação por sete dias.

\section{Estudo macro e microscópico}

Em relação ao inventário das fossas ilíacas observaram-se aderências (classificadas em graus de zero a V) (Swolin et al, 1966, apud Ozel et al. 2005)15, hematomas, secreções, necrose, plastrão, abscesso, peritonite, encistamento, acomodação e incorporação da prótese, obstrução e fístulas intestinais e migração da prótese.

Os fragmentos de cada peça cirúrgica foram preparados para o estudo histológico com microscopia óptica em aumentos de 100X e 400X. Estes foram corados por Hematoxilina/Eosina (H/E) e Tricrômio de Masson (TM). Ao término do preparo das lâminas elegeu-se o fragmento central como o de melhor expressão sobre o experimento e, portanto, 80 lâminas foram estudadas por um único patologista que não sabia a que grupo pertencia cada animal.

Os achados microscópicos pesquisados nas fases inflamatória (aguda e crônica) e reparadora foram: crosta fibrinoleucocitária, necrose focal, depósito de fibrina, exsudato neutrofílico, edema, dilatação linfática, congestão vascular, hemorragia focal, exsudato eosinofílico, infiltrado mononuclear, infiltrado macrofágico, granulomas, neoformação vascular, proliferação fibroblástica e fibrose.

A intensidade das alterações histológicas foi classificada em: (0), (+), (++) e (+++) conforme fosse ausente, pequena, moderada e acentuada (Oliveira, 1989; Sousa, 1989) $)^{16,17}$.

\section{Análise estatística}

Foram utlitizados os seguintes testes: McNemar para comparação das próteses intragrupo; exato de Fisher para comparação de cada prótese entre os grupos; Wilcoxon para apreciação quantitativa do grau de aderência das vísceras e epíploon com as próteses; T pareado para análise da média da diferença de peso dos animais no pré e no pós-operatório.

O nível crítico adotado para a definição de diferença significativa foi menor ou igual a $5 \%(p<0,05)$.

\section{RESULTADOS}

Os 20 animais sobreviveram ao experimento até o dia estabelecido para a eutanásia, sem complicações. No inventário da cavidade abdominal não foram observadas peritonite, obstrução ou fístulas intestinais. Ocorreu diferença significativa entre a média do peso no pré e a do pós-operatório no grupo $\mathrm{A}(\mathrm{p}=0,0047)$.

\section{Análise macroscópica}

Nos grupos A e B não foram observados secreções, necrose, abscesso, plastrão, fístula e migração das próteses.

Em todos os animais, os dois tipos de prótese ajustaram-se bem às regiões inguinais caracterizando boa acomodação, A incorporação ao peritônio parietal deu-se com a prótese de PPL em todos os animais.

Nos dois grupos, as aderências com a prótese de DF ocorreram apenas na borda das próteses, mantendo sua face visceral livre (Tabela 2).

Na comparação entre as próteses em cada grupo pelo teste de McNemar, não se encontrou diferença significativa entre as próteses de DF e de PPL quanto à prevalência e o grau de aderências com a bexiga, intestino delgado e trompas.

Na comparação intragrupo dos dois tipos de próteses, houve diferença significante na prevalência das aderências com o omento no grupo $A(p=0,05)$, mas não houve no grupo $B(p=0,08)$ (Tabela 3 ).

Não houve diferença significante entre os dois tipos de próteses quanto à prevalência de aderências com o disco central de PPL nos grupos A $(p=0,08)$ e $B(p=0,08)$.

Nas próteses de DF as aderências do omento ocorreram, na média dos dois grupos, em $65 \%$ dos cães nas bordas das próteses mantendo livre a face visceral, sendo que destas, 35\% em média, a aderência se fazia com o disco de PPL na face parietal da prótese.

Na comparação intragrupo entre os dois tipos de próteses quanto ao grau de intensidade de aderências, pelo teste de Wilcoxon, houve diferença significante nos grupos A e B com o omento ( $p=0,0034 ; p=0,0008)$ respectivamente.

\section{Análise microscópica}

As variáveis relacionadas à fase inflamatória foram analisadas em lâminas coradas pela Hematoxilina/ Eosina (H/E).

Grupo A: Não foram encontrados depósito de fibrina, dilatação linfática e granulomas tanto com a prótese de DF como com a de PPL. Crosta fibrinoleucocitária, necrose

Tabela 2 - Percentual de aderências do omento relativo ao local de aderência nas próteses de DF.

\begin{tabular}{lccc}
\hline Local & \multicolumn{3}{c}{ Grupos } \\
\cline { 2 - 4 } & A & B & Média \\
\hline Com o disco de PPL & 30 & 30 & 30 \\
Com a borda da prótese & 30 & 40 & 35 \\
Aderência global & 60 & 70 & 65 \\
\hline
\end{tabular}


focal, exsudato eosinofílico e neutrofílico foram encontrados apenas com a prótese de DF em prevalência baixa sem significado estatístico $(p>0,05)$ (Tabela 4, Figura 1).

Grupo B: A comparação intragrupo mostrou não haver diferença significativa entre os dois tipos de próteses. Edema, congestão vascular, hemorragia focal, infiltrado mononuclear e infiltrado macrofágico tiveram prevalência alta e com graus variáveis de intensidade de leve a intenso.

As demais alterações microscópicas constantes da avaliação não foram encontradas no grupo $B$.

As variáveis relacionadas à fase reparadora foram analisadas em lâminas coradas pelo Tricrômio de Masson (TM).

Grupo A: Neoformação vascular, proliferação fibroblástica e fibrose ocorreram em $100 \%$ dos casos para ambas as próteses. Não houve diferença significativa na prevalência desses achados entre as próteses de DF e PPL ( $p>0,05)$ (Tabela 5).

Grupo B: A neoformação vascular ocorreu em $100 \%$ dos casos, para ambas as próteses, enquanto a proliferação fibroblástica e a fibrose ocorreram em 80 a 100\% para ambas as próteses. Não houve no grupo B diferença significativa entre as próteses de DF e PPL quanto à prevalência desses achados microscópicos na fase reparadora $(p>0,05)$ (Tabela 5).
Na análise estatística a aplicação do teste de Fisher para a comparação intergrupos não demonstrou diferença significante $(p>0,05)$ entre os grupos $A$ e B quanto a prevalência e grau de neoformação vascular, proliferação fibroblástica e fibrose.

\section{DISCUSSÃO}

Uma das preocupações da hernioplastia é a manutenção da integridade dos tecidos da região e a possibilidade de sua utilização no reparo do defeito herniário. Em pacientes debilitados, nas hérnias gigantes, com perda de estrutura e nas hérnias operadas múltiplas vezes é difícil o tratamento utilizando-se somente as estruturas da região afetada. Nessa situação, uma alternativa útil é o emprego de próteses ou telas 5 .

O animal escolhido para estudo foi o cão do gênero feminino, pois apresenta tamanho favorável para manipulação, com abertura da parede abdominal infraumbilical mais fácil que no sexo masculino e porque a anatomia da região inguinal é semelhante à do homem ${ }^{18}$. O princípio do "manchão de pneu" enunciado por René Stoppa com o uso da prótese pré-peritoneal e o princípio da técnica "livre de tensão" de Lichteinstein, somados à faci-

Tabela 3 - Percentual de aderência do omento com as próteses.

\begin{tabular}{llclc}
\hline Grau & \multicolumn{2}{c}{ A } & DF & B \\
\cline { 2 - 5 } & DF & PPL & 30 & 0 \\
\hline 0 & 40 & 0 & 50 & 10 \\
I & 50 & 40 & 20 & 50 \\
II & 10 & 40 & - & 40 \\
III & - & 20 & - & - \\
V & - & - & - & - \\
p (prevalência) & - & - & 0,08 & 0,08 \\
p (intensidade) & 0,05 & 0,05 & 0,0008 & 0,0008 \\
\hline
\end{tabular}

Tabela 4 - Percentual de achados microscópicos na fase inflamatória do grupo A.

\begin{tabular}{|c|c|c|c|c|c|c|c|c|c|}
\hline \multirow[t]{2}{*}{ Achados } & \multicolumn{5}{|c|}{ DF } & \multicolumn{3}{|c|}{ PPL } & \multirow[t]{2}{*}{$P$} \\
\hline & 0 & $1+$ & $2+$ & $3+$ & 0 & $1+$ & $2+$ & $3+$ & \\
\hline 1. Crosta fibrino-leucocitária & 90 & 10 & - & - & 100 & - & - & - & - \\
\hline 2. Necrose focal & 70 & 30 & - & - & 100 & - & - & - & - \\
\hline 3. Depósito de fibrina & 100 & - & - & - & 100 & - & - & - & - \\
\hline 4. Exsudato eosinófílico & 90 & - & 10 & - & 100 & - & - & - & - \\
\hline 5. Exsudato neutrofílico & 70 & 10 & 10 & 10 & 100 & - & - & - & - \\
\hline 6. Dilatação linfática & 100 & - & - & - & 100 & - & - & - & - \\
\hline 7. Granulomas & 100 & - & - & - & 100 & - & - & - & - \\
\hline 8. Edema & - & 20 & 70 & 10 & 20 & 50 & 10 & 20 & 0,16 \\
\hline 9. Congestão vascular & - & 10 & 40 & 50 & - & 10 & 50 & 40 & 1,00 \\
\hline 10. Hemorragia focal & 30 & 40 & 10 & 20 & 20 & 40 & 20 & 20 & 0,32 \\
\hline 11. Infiltrado mononuclear & - & 10 & 50 & 40 & - & 10 & 30 & 60 & 1,00 \\
\hline 12. Infiltrado macrofágico & - & 20 & 50 & 30 & - & 10 & 50 & 40 & 1,00 \\
\hline
\end{tabular}



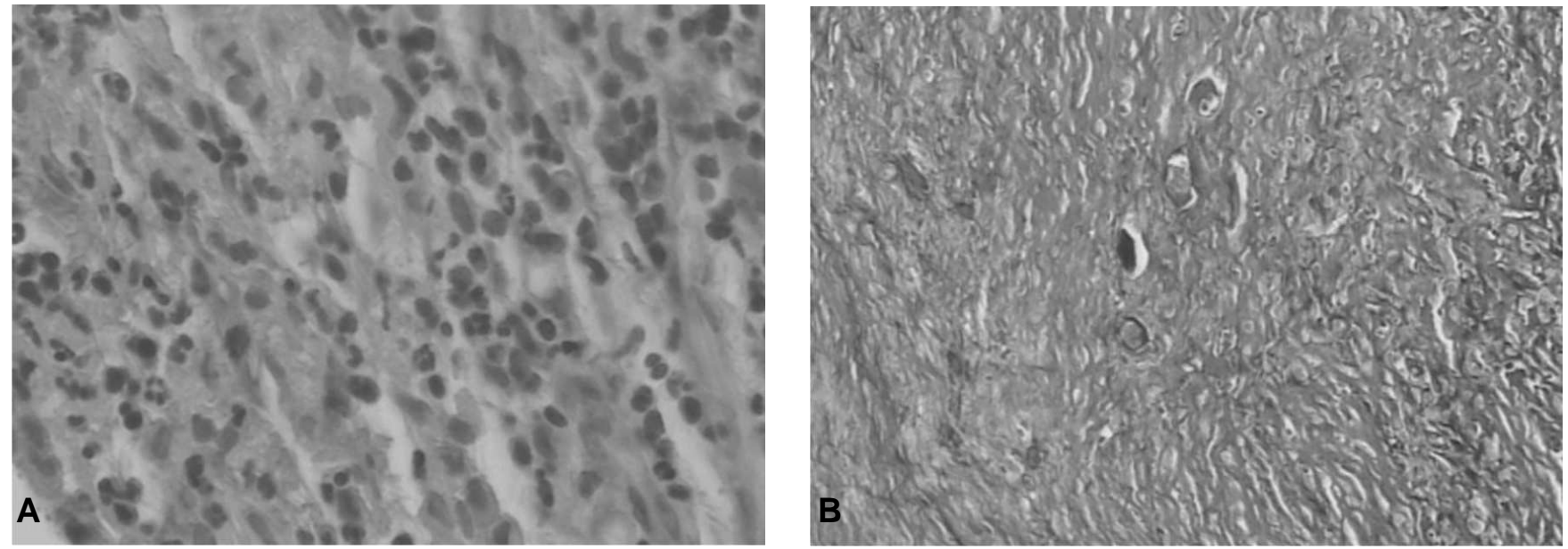

Figura 1 - A - Exsudato neutrofílico intenso em tecido colhido junto à face parietal da prótese de DF (H/E /400X). B - Neoformação vascular de grande intensidade em tecido colhido junto à face parietal da prótese de DF (TM /100X).

lidade da colocação da prótese intraperitoneal por videolaparoscopia11 motivaram esta pesquisa em busca de uma prótese de DF. Esta composição é esperada ter bom potencial de incorporação à parede inguinal, resistência mecânica semelhante à dos tecidos da região a ser implantada e com baixo poder de aderência às vísceras abdominais.

A prótese de PTFE é no momento a mais recomendada, mas apresenta também complicações como infecção, aderências, obstrução e fístulas intestinais em proporções menores do que a prótese de PPL; todavia, o custo alto inviabiliza seu uso de forma rotineira, sobretudo nos pacientes que utilizam o SUS.

Assim, optou-se por desenvolver uma prótese que pudesse ser usada no tratamento das hérnias inguinocrurais, mediante uma técnica que não desrespeita princípios consagrados e que seja de fácil execução e custos acessíveis.

Com base nos trabalhos desenvolvidos no Departamento de Cirurgia e Anatomia e Bioquímica e Imunologia da FMRP da USP por Mrué $(1995,2000)^{12,13} \mathrm{e}$ Sousa $(2005)^{14}$ que mostraram que a BML tem boa tolerância junto às vísceras e induz o processo de reparação tecidual, propôs-se a conjunção destas propriedades às já conheci- das características da prótese de PPL de incorporação aos tecidos, criando assim uma prótese de DF.

A prótese de PPL apresenta praticamente todas as características descritas por Cumberland (1952) ${ }^{19}$ como material sintético ideal para reforço em defeitos herniários, porém favorece a reação de corpo estranho com indução da formação de aderências quando colocada em contato com as vísceras.

A BML, com base nos estudos realizados até o momento, possui também todas essas características, mas não sofre incorporação pelos tecidos e tem a vantagem de não se aderir às vísceras eventualmente em contato.

Mantida a importância dessas propriedades, decidiu-se nesta pesquisa testar a prótese de DF, usando o benefício da incorporação do PPL voltado à parede inguinal, e da não incorporação do látex (visando à prevenção de aderências) voltado para a cavidade peritoneal.

A avaliação macroscópica baseou-se nos achados locais da inguinoplastia, definindo como específicos as aderências do omento pela sua particular importância.

Não foi encontrado encistamento da prótese pelos tecidos. A acomodação e a incorporação ocorreram em todos os animais dos dois grupos.

Tabela 5 - Percentual de achados microscópicos na fase reparadora nos grupos A e B.

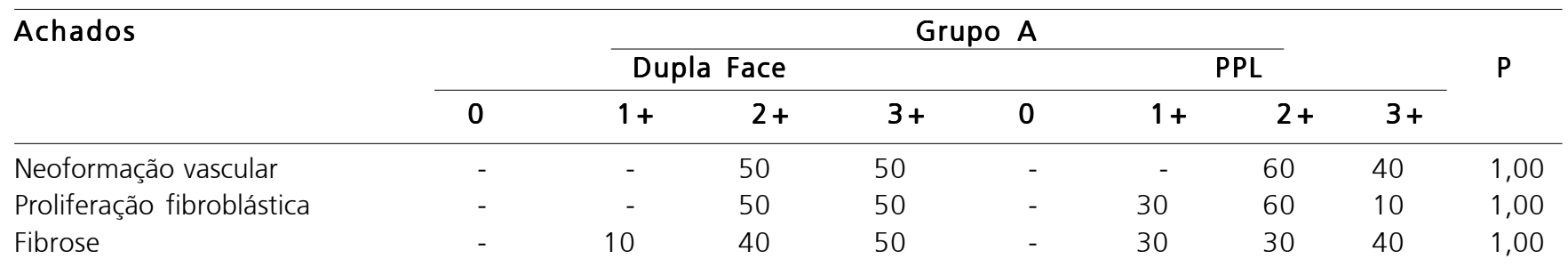

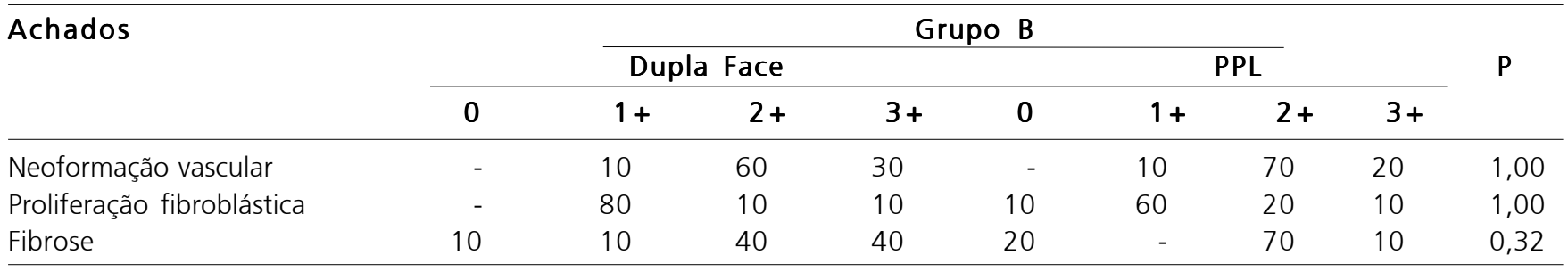


Aderências de vísceras (bexiga, intestino delgado e trompas) com as próteses ocorreram em baixa prevalência, aparentemente com frequência um pouco maior com a bexiga, provavelmente pela proximidade desta com as próteses. As aderências foram de maior intensidade com a prótese de PPL (controle). Em nenhum grupo ocorreu diferença significante das aderências com as vísceras entre as próteses de DF e PPL, com p>0,05, para prevalência e para intensidade.

Aderências do omento ocorreram em todas as próteses de PPL e em $60 \%$ e $70 \%$ com as próteses de DF respectivamente nos grupos $A$ e $B$, porém com diferença significante $(p=0,05)$ somente no grupo $A$. Todavia, as aderências do omento com a prótese de PPL foram de maior intensidade do que com a DF, nos dois grupos, com $p=0,0034$ e 0,0008 respectivamente para os grupos A e B.

O processo inflamatório gerado pela presença de um corpo estranho do tipo PPL induziu fortes aderências com o omento. Goldenberg et al. (2005) compararam o percentual de aderências entre próteses de PPL e Vyproß (PPL/ Poligalactina) implantados na região inguinal pré-peritoneal de coelhos; os resultados mostraram $78,6 \%$ de aderências com a prótese de PPL e 85,7\% com a prótese de Vypro®.

As aderências do omento com as próteses de PPL fizeram-se na totalidade com sua face visceral; ao contrário, as aderências com a prótese de DF foram observadas apenas nas bordas, no local de aplicação dos grampos de fixação (em média $65 \%$ nos dois grupos), sendo que destas, 35\% em média, a aderência se fazia com o disco de PPL na face parietal da prótese, ocorrência aparentemente facilitada pelos espaços deixados entre os grampos de fixação. Em proporções semelhantes, esse fato ocorreu nos dois grupos, apesar da diferença de tempo pós-operatório entre eles.

Possivelmente uma prótese de DF com uma aba de látex mais larga associada à aplicação de maior número de grampos de fixação, com intervalo menor entre si, dificultaria ou impediria a migração do omento em direção ao disco de PPL.

Componentes da fase inflamatória aguda como crosta fibrinoleucocitária, necrose focal, exsudado eosinofílico e neutrofílico ocorreram somente na prótese de DF do grupo A e em baixa prevalência, sem diferença significante $(p>0,05)$ com a prótese de PPL. Estes mesmos achados não foram evidenciados nas próteses de DF e PPL no grupo B.

$\mathrm{Na}$ fase de reparação a comparação das duas próteses em cada grupo, demonstrou, com a coloração das lâminas pelo TM, que no grupo $A$, a neoformação vascular, a proliferação fibroblástica e a fibrose foram observadas em todos os casos, prevalecendo em intensidade moderada nas duas próteses. No grupo B, a neoformação vascular ocorreu em todos os casos nas duas próteses em grau moderado e intenso. Nenhum dos resultados, nos dois grupos apresentou diferença significativa entre as duas próteses. Os tecidos podem ser reparados por regeneração com completa restauração da forma e função ou por reparação com tecido conjuntivo e formação de cicatriz. Os principais componentes do reparo por tecido conjuntivo são: neoangiogênese, migração e proliferação de fibroblastos, síntese de colágeno e remodelação 20 .

Estes resultados semelhantes entre as duas próteses são compreensíveis, pois as lâminas examinadas foram preparadas a partir da amostra do fragmento central da peça cirúrgica que representa o tecido da parede inguinal que estava em contato direto com a prótese de PPL (controle) e, da mesma forma, com o disco de PPL da prótese de DF.

A prótese de PPL, certamente a mais empregada na prática cirúrgica e com comportamento muito bem estudado foi um bom modelo de comparação. Tanto o PPL como o látex são produtos adquiridos a custos acessíveis e a sua associação deu origem à prótese de DF que somou as vantagens da incorporação induzida pelo PPL à desejável biocompatibilidade do látex junto às vísceras abdominais.

Em conclusão: A prótese de dupla face na sua face parietal soma as vantagens do potencial de incorporação aos tecidos observados com o polipropileno às de biocompatibilidade do látex na sua face visceral. A pequena distância entre o disco de polipropileno e a borda da prótese de dupla face $(2 \mathrm{~cm})$ aliada à sua fixação com apenas cinco grampos é insuficiente para evitar que o epíploon migre em direção ao processo inflamatório desencadeado pelo polipropileno na face parietal.

\section{A $B$ S $S T$ R A C T}

Objective: To asses the morphological features of the behavior of a double-sided prostheses using inguinoplasty laparotomy in dogs with latex side turned to the visceras. Methods: Twenty dogs were divided into two groups of 10 and submitted into infraumbilical laparotomy with double-sided prostheses fixed in an inguinal area and in the other side area a control prostheses of polipropilene (PPL). Macroscopics itens were studied on the $14^{\text {th }}$ and $28^{\text {th }}$ day post-operatory, and they were related to obstruction and intestinal fistulas, encystation, fusion and especially sticker. The microscopic analysis covered the inflammatory process in its acute, chronic and restored phase Results: Infectious process, obstruction or intestinal fistula did not happen. The prostheses presented good accommodation and incorporation. The stickers happened with more prevalent and intensity with the PPL $(p<0,05)$ prostheses. The stickers with double-sided prostheses happened $65 \%$ in its two groups average, from these $35 \%$ in average the sticker happened with the PPL disc in the parietal side. The macroscopic itens analysis did not show any statistical difference between prostheses $(p>0,05)$. Conclusion: The double-sided prostheses in its parietal side adds the advantages of the incorporation's potential to the noticed material with PPL to the biocompatibility from the latex in its visceral side. The little distance between the PPL disc and the edge of the double-sided prostheses $(2 \mathrm{~cm})$ allied to its sticking with just five staples is not enough to avoid gaps, through which the epíploon migrated towards to the inflammatory process provoked by PPL in the parietal side.

Key words: Hernia. Peritoneal cavity. Prostheses. Polypropylenes. Latex. Dogs 


\section{REFERENCIAS}

01. Lex A, Valtorta A. Hérnia, aspecto clínico e cirúrgico. São Paulo: Panamed, 1984

02. Romeo $A B$, Villas-Boas $M L$, Jesuíno PA. Herniorrafia inguinal videolaparoscópica: a conquista do merecido lugar. s.d. Disponível em: http://brgeocities.com/bhmed_leoaraujo/herniorrafia_ inguinal_videolapar. Acesso em: 14 ago 2006.

03. Nyhus LM, Condon RE. El abordaje preperitoneal y la plástica de la hernia inguinal con el ligamento iliopubiano. In: Nyhus LM, Condon RE. Hernia. $3^{\text {a }}$ ed. Philadelphia: Panamericana; 1994. p. 160-90.

04. Wantz GE. La técnica canadiense para la plástica de la hernia inguinal. In: Nyhus LM, Condon RE. Hernia. $3^{a}$ ed. Philadelphia: Panamericana; 1994. p. 235-50.

05. Silva $A L$, Petroianu A. Próteses. In: Silva AL. Hérnias. $2^{a}$ ed. São Paulo:

Roca; 2006. p. 842-8.

06. Usher FCA. New plastic prosthesis for repairing tissue defects of the chest and abdominal wall. Am J Surg. 1959; 97: 6299-633.

07. Falci F. Marlex mesh no tratamento da hérnia inguinal do adulto (análise de 100 casos operados). Hospital. 1969; 75(1):161-73.

08. Stoppa R, Petit J, Henry X. Plasties des hernies de I'aine par voie mediane sous-péritonéale. Acta Cirur. 1972; 5(488).

09. Lichteinstein IL, Shore JM. Exploding the myths of hernia repair. Am J Surg. 1976: 132(3):307-15.

10. Fitzgibbons RJ, Salerno GM, Fillipi CJ, Hunter WJ, Watson PA. Técnica laparoscópica intraperitoneal com tela para o reparo da hérnia inguinal indireta. Ann Surg. 1994; 219:144-56.

11. Fitzgibbons RJ. Laparoscopic inguinal herniorrhapy. San Francisco, 1993. (Personal comunication and Postgraduate Course of American College of Surgeons).

12. Mrué F. Substituição do esôfago cervical por prótese biossintética de látex: estudo experimental em cães (dissertação). Universidade de São Paulo: Ribeirão Preto; 1996.

13. Mrué, F. Neoformação tecidual induzida por biomembrana de látex natural com polilisina: aplicabilidade na neoformação esofágica e da parede abdominal: estudo experimental em cães. Dissertação (Doutorado) - Faculdade de Medicina de Ribeirão Preto, Universidade de São Paulo, Ribeirão Preto, 2000
14. Sousa LH. Avaliação morfológica da utilização da prótese de látex na inguinoplastia videolaparoscópica: estudo experimental em cães (dissertação). Universidade de São Paulo: Ribeirão Preto; 2005.

15. Ozel H, Avsar FM, Topaloglu S, Sahin M. Induction and assessment methods used in experimental adhesion studies. Wound Repair Regen. 2005; 13(4):358-64.

16. Oliveira PG. Estudo dos efeitos de uma prostaglandina sintética, o misoprostol, sobre a cicatrização de anastomoses no intestino grosso de ratos (dissertação). Universidade de São Paulo: Ribeirão Preto; 1989.

17. Sousa, J. B. Estudo da cicatrização em anastomoses no intestino delgado de coelhos tratados com diclofenaco sódico (dissertação). Universidade de São Paulo: Ribeirão Preto; 1989.

18. Sousa LH. Técnica cirúrgica transabdominal pré-peritoneal para tratamento da hérnia inguinal: imersão em treinamento de cirurgia videolaparoscópica. 1994. (Vídeo).

19. Cumberland $\mathrm{VH}$. A preliminary report on the use of prefabricated nylon weave in the repair of ventral hernia. Med J Aust. 1952; $1: 143-4$

20. Kumar V, Abbas AK, Fausto N, Mitchell RN. Reparo tecidual: regeneração, cicatrização e fibrose. In: Kumar $\mathrm{V}$, et al. Robbins, patologia básica. $8^{a}$ ed. Rio de Janeiro: Elsevier; 2008. p. 63.

Recebido em 28/11/2008

Aceito para publicação em 29/01/2009

Conflito de interesse: nenhum

Fonte de financiamento: nenhuma

Como citar este artigo:

Andrade LC, Ceneviva R, Coutinho-Netto J Silva Júnior OC, Santos JS, Sukeda DH. Aspectos morfológicos da utilização intraperitoneal de prótese de dupla face (biomembrana de látex e tela de polipropileno) na inguinoplastia em cães. Rev Col Bras Cir. [periódico na Internet] 2009; 36(5). Disponível em URL: http://www.scielo.br/rcbc

\section{Endereço para correspondência:}

Luiz Carlos de Andrade

E-mail: luizcarlosandrade@artefinal.com.br 